\title{
PENERAPAN MEDIA LAGU ANAK UNTUK MENINGKATKAN KREATIVITAS BERBAHASA ANAK DI SD KARTIKA SILIWANGI 7, KOTA CIREBON
}

\author{
Nuning Wahyuningsih, Hesti Muliawati, dan Andi Sutisno \\ Pendidikan Bahasa Indonesia \\ Universitas Swadaya Gunung Jati
}

\begin{abstract}
ABSTRAK
Pemerolehan kosakata anak SD ternyata masih rendah, padahal sesuai dengan tahapan pemerolehannya seharusnya sudah memiliki beragam kosakata. Tujuan pembelajaran bahasa Indonesia pada tingkat SD yaitu agar siswa memiliki kemampuan berkomunikasi secara efektif dan efisien sesuai dengan etika yang berlaku baik secara lisan maupun tulisan. Hal tersebut tentu saja sejalan dengan tujuan utama pembelajaran bahasa Indonesia di SD ialah siswa mampu menggunakan bahasa Indonesia disertai dengan rasa bangga sebagai bahasa persatuan. Dengan menggunakan media lagu anak diharapkan dapat menambah kreativitas berbahasanya. Tujuan penelitian ini adalah untuk mengetahui keefektifan penerapan media lagu anak yang dapat meningkatkan kreativitas berbahasa anak kelas 4 SD Kartika Siliwangi 7, Kota Cirebon, dan untuk mengetahui aktivitas siswa Kelas 4 SD Kartika Siliwangi 7 Kota Cirebon, dalam kreativitas berbahasa dengan menggunakan media lagu anak. Adapun teknik penelitian yang digunakan ialah eksperimen dengan menggunakan metode tindakan kelas. Sampel dalam penelitian ini ialah siswa SD Kelas 4 yang masih dalam tahap pemerolehan bahasa praoperasional kurang dari 10 tahun.
\end{abstract}

Kata kunci: Pemerolehan bahasa, media lagu, dan kreativitas berbahasa.

\section{PENDAHULUAN}

Bahasa merupakan seperangkat sistem lambang bunyi yang arbitrer dan berfungsi sebagai alat komunikasi. Salah satu fungsi utama dari bahasa yaitu sebagai alat komunikasi antara individu yang satu dengan individu lainnya dan sebagai identitas suatu masyarakat. Maka dari itu, sebagai warga negara Indonesia, meskipun setiap daerah memiliki bahasa yang beragam, tetapi dalam situasi formal wajib menggunakan bahasa Indonesia yang baik dan benar. Dengan demikian, sebagai bentuk pelestarian dan wujud identitas bangsa, maka bahasa Indonesia sudah dipelajari sejak di bangku Sekolah Dasar bahkan hingga Perguruan Tinggi.

Bagi siswa SD, bahasa Indonesia merupakan bahasa kedua setelah bahasa ibu yang mereka kuasai (bahasa daerah). Dalam hal ini, siswa SD masih berada dalam tahap pemerolehan bahasa kedua khususnya kelas rendah yaitu kelas 1, 2, dan 3. Sedangkan kelas tinggi yaitu kelas 4, 5, dan 6 sudah masuk dalam tahap 
pembelajaran bahasa Indonesia. Meskipun pada dasarnya sama, antara kelas rendah dan tinggi memiliki tujuan pembelajaran bahasa Indonesia yang sama yakni sebagai bentuk rasa bangga menggunakan bahasa persatuan sejak dini dan mampu menggunakannya secara efektif, baik lisan maupun tulisan.

Dalam tahap pemerolehan dan pembelajaran bahasa kedua ini guru harus benar-benar memahaminya, khususnya guru bahasa Indonesia pada kelas 4 SD. Guru harus kreatif dan inovatif agar siswa mampu menunjukan kreativitas berbahasa pada siswanya. Salah satunya yakni dengan menggunakan media lagu anak. Lagu anak bagi anak-anak di bawah usia 8 tahun sangat menarik bahkan menyenangkan. Tak jarang para pengajar pada jenjang nonformal (TK) mengajarkan segalanya melalui lagu. Dunia anak sangat identik dengan penuh kegembiraan dan salah satunya dapat dilakukan melalui lagu yang di dalam liriknya membuat pemikiran anak lebih kreatif dan lebih memahami kosakata.

Kreativitas pada anak dalam tahap perkembangan sangat dipengaruhi oleh lingkungan sekitarnya. Dengan siapa mereka berinteraksi, kapan, dan dalam kegiatan yang seperti apa. Banyak sekali kegiatan anak yang dapat memunculkan kreativitas. Salah satunya dengan menggunakan media lagu. Dengan lagu, anak-anak dapat mengekspresikan segaa bentuk perasaannya, sekaligus memadukan pergembangan kognitif dan psikomotoriknya.

\section{KAJIAN TEORI}

Salah satu tujuan pembelajaran bahasa Indonesia di SD ialah untuk menumbuhkan rasa bangga dan cinta sejak dini terhadap bahasa Indonesia sebagai bahasa persatuan dan bahasa nasional. Selain itu, agar siswa SD mampu menggunakan bahasa Indonesia yang baik secara lisan maupun tulisan dalam situasi formal. Bagi masyarakat Indonesia, bahasa Indonesia merupakan bahasa kedua karena bahasa pertamanya ialah bahasa daerah.

Sesuai dengan Kurikulum 2013 revisi bahwa di SD materinya tematik. Begitu juga dalam pelajaran Bahasa Indonesia Kelas 4 KD 3.1.1. Mencermati puisi anak/syair lagu (berisi ungkapan kekaguman, kebanggaan, hormat kepada orang tua, persahabatan) yang diperdengarkan dengan tujuan untuk kesenangan. Materi intinya yaitu mencermati lagu anak agar dipahami dan menambah kosakata baru bagi anak-anak SD kelas 4 .

Proses seseorang mulai mengenal komunikasi dengan lingkungannya secara verbal disebut dengan pemerolehan bahasa pertama. Pemerolehan bahasa pertama terjadi apabila seseorang, sejak ia dilahirkan tanpa bahasa kini memperoleh suatu bahasa. Pada masa pemerolehan bahasa, seseorang akan 
tampak lebih mengarah pada fungsi komunikasi daripada bentuk bahasanya. Hal tersebut sesuai dengan pendapat Fromkin dan Roadman (Ariwibowo, 2008: 18) mereka mendefinisikan bahwa pemerolehan bahasa merupakan sesuatu yang mempunyai permulaan gradual dan muncul dari prestasiprestasi motorik sosial serta kognitif pralinguistik. Pemerolehan bahasa pertama sangat erat hubungannya dengan perkembangan kognitif yang pertama, jika seseorang dapat menghasilkan ucapanucapan berdasarkan pada tata bahasa yang terautur dan rapi, maka dapat disimpulkan bahwa anak tersebut telah mengusai bahasanya dengan baik.

Perkembangan kreativitas erat kaitannya dengan perkembangan kognitif karena perwujudan dari kemampuan otak. Clark (dalam Asrori 2012: 60-61) bahwa kecerdasan berbahasa terdapat pada belahan otak kiri, sedangkan otak kanan mengarah pada cara berpikir menyebar (divergent thinking). Dengan demikian, bahwa otak kanan sangat berkaitan dengan keativitas.

Senada dengan hal tersebut, Torrance (Asrori, 2012: 63) menjelaskan bahwa kreativitas muncul dikarenakan potensi yang berkembang di dalam dirinya yang sangat dipengaruhi oleh lingkungannya. Selama berinteraksilah kreativitas itu muncul dan berkembang karena menghadapi berbagai perosoalan yang terdapat di lingkungan sekitarnya. Agar kreativitas pada individu itu dapat diwujudkan, diperlukan kekuatankekuatan pendorong dari luar dengan proses belajar dan pengalaman dari lingkungannya. Hal yang sama juga diungkapkan oleh Guilford (2012: 61) bahwa kreativitas mengacu pada kemampuan yang menandai ciri-ciri kreatif. Dengan demikian, dapat disimpulkan bahwa kreativitas ialah kemampuan untuk menciptakan sesuatu yang baru.

Adapun faktor-faktor yang dapat mempengaruhi kreaitvias (Munandar: 74), diantaranya.

a. Usia;

b. Tingkat pendidikan orang tua;

c. Tersedianya fasilitas; dan

d. Penggunaan waktu luang.

Bagi seorang anak, faktor utama dalam menentukan kreativitas ialah lingkungan pertamanya, yaitu keluarganya. Maka tidak salah jika tingkat pendidikan orang tua, kelangkapan fasilitas, dan penggunaan waktu luang sangat mempengaruhi terbentuknya kreativitas seorang anak.

Sesuai dengan tahapan pemerolehan bahasanya anak SD kelas 4 sekitar usia 6 dan 7 tahun berada dalam tahap praoperasional yakni masa-masa perkembangan bahasa yang sangat pesat. Begitu juga kreativitas berbahasa pada anak pada kelas 4 SD banyak 
menghasilkan kosakata baru sesuai dengan pengalaman yang diperoleh dari lingkungan sekitarnya.

Pada dasarnya media yang digunakan untuk kegiatan pembelajaran adalah media komunikasi. Salah satu fungsi media pembelajaran yaitu untuk mempermudah pemahaman siswa dalam penjelasan materi pembelajaran. Saat ini, di era milenial media pembelajaran digital adalah salah satu media yang paling efektif digunakan untuk mempermudah pemahaman siswa. Sekaitan dengan media digital, peneliti memanfaatkan youtobe lagu-lagu anak yang akan ditayangkan saat pembelajaran Bahasa Indonesia di kelas 4.

Sejak masih belum bisa berbicara, anak-anak sudah diperkenalkan dengan bernyanyi. Meskipun belum bisa bernyanyi, tetapi anak-anak sudah mampu meresponsnya. Lagu anak isinya menarik, energik, dan membuat anak-anak bahagia saat menyanyikannya. Dengan demikian diharapkan pada saat digunakannya media lagu anak ini dapat menambah kreativitas berbahasa anak.

\section{METODOLOGI PENELTIAN}

Penelitian ini menggunakan metode
penelitian tindakan kelas. Dengan

menggunakan teknik tes dan observasi. Tes digunakan untuk mengukur sejauh mana penggunaan media lagi anak dalam meningkatkan kreativitas berbahasa anak. Sedangkan observasi ialah suatu proses pengamatan yang tersusun secara mendalam. Dalam hal ini peneliti mengamati secara langsung proses kerja yang dilakukan oleh siswa kelas 4 tersebut.

Penelitian ini dilakukan di SD Kartika Siliwangi 7 Kota Cirebon, dengan sampel kelas 4 dengan jumlah siswa 28 orang. Adapun latar belakang pemilihan sampel didasarkan karena siswa tersebut bersekolah di sekolah yang letaknya strategis berada di kota dan latar belakang orangtua yang mempunyai pendidikan menengah ke atas. Hal didasarkan pada kenyataan bahwa kreativitas anak sangat dipengaruhi oleh pendidikan orang tua dan lingkungan sekitarnya. Sumber data dalam penelitian ini yaitu berupa tayangan video yang diperoleh dari youtobe, berupa lima jenis lagu anak, diantaranya "Aku Anak gembala, Naik Delman, Balonku, Naik-naik ke puncak gunung, Bintang Kecil, dan Tik-tik bunyi hujan”. Data dalam penelitian ini yaitu berupa kelima lirik lagu tersebut yang isinya tidak lengkap (rumpang).

\section{PEMBAHASAN}

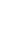


1. Penelitian ini dilaksanakan pada hari Sabtu, 2 Maret 2019, pukul 08.10 s.d. 09.10 di SD Kartika Siliwangi XIX-7 yang beralamat di Jl. Kesambi No 138, Kecamatan Cirebon, Kota Cirebon. Subjek penelitian ini yaitu siswa kelas 4 yang berjumlah 35 orang, tetapi pada saat penelitian berlangsung siswa yang hadir berjumlah 34 orang, terdiri dari 20 siswa perempuan dan 14 siswa lakilaki. Saat penelitian ini berlangsung, siswa sangat antusias dan bersemangat dalam belajar pada pelajaran bahasa Indonesia.

2. Saat penelitian, tidak semua siswa hadir, dikarenakan ada yang sakit, jadi yang hadir berjumlah 34 orang. Dari ke-34 siswa, setelah dianalisis, hanya 26 siswa yang memenuhi kriteria untuk dianalisis hasil tulisannya. Berikut ini data siswa disertai judul lagunya.

Tabel 1

Judul Lagu dan Data Siswa

\begin{tabular}{|l|l|l|l|}
\hline No & \multicolumn{1}{|c|}{ Judul Lagu Anak } & \multicolumn{1}{|c|}{ Subjek Penelitian } & Subjek yang Tidak Sesuai \\
\hline 1 & Becak & S1, S2, S3, S4, dan S5 & S4 \\
\hline 2 & Satu-Satu Aku Sayang Ibu & $\begin{array}{l}\text { S6, S7, S8, S9, S10, dan } \\
\text { S11 }\end{array}$ & S6, S8, dan S10 \\
\hline 3 & Balonku Ada Lima & $\begin{array}{l}\text { S12, S13, S14, S15, dan } \\
\text { S16 }\end{array}$ & S12 \\
\hline 4 & Naik Kereta Api & $\begin{array}{l}\text { S17, S18, S19, S20, S21, } \\
\text { S22, dan S23 }\end{array}$ & S17 dan S18 \\
\hline 5 & Bangun Tidur & $\begin{array}{l}\text { S24, S25, S26, S27, S28, } \\
\text { dan S29 }\end{array}$ & - \\
\hline 6 & Aku Anak Gembala & $\begin{array}{l}\text { S30, S31, S32, S33, dan } \\
\text { S34 }\end{array}$ & S31 \\
\hline \multicolumn{2}{|c|}{ Jumlah Subjek Penelitian } & 34 siswa & siswa \\
\hline
\end{tabular}

Berdasarkan tabel di atas, dari ke tiga puluh emat siswa, yang dijadikan sampel penelitian untuk dianalisis, berjumlah 26 siswa. Tahap selanjutnya yaitu menganalisis pemunculan kosakata baru yang terdapat dari tulisan siswa. 
Berikut ini adalah hasil rekapitulasi

kreativitas berbahasa siswa pada keenam lagu

anak yang dijadikan media.

Tabel 2

\section{Hasil Kreativitas Berbahasa Siswa Lagu "Becak"}

\begin{tabular}{|c|c|c|}
\hline Subjek & Lirik lagu "Becak" & Kreativitas Berbahasa \\
\hline S1 & \multirow{3}{*}{$\begin{array}{l}\text { Saya mau tamasya } \\
\text { berkeliling-lilimg kota } \\
\text { Hendak melihat-lihat keramaian yang ada } \\
\text { Saya, panggilkan becak, becak....becak... } \\
\text { Kereta tak berkuda, coba bawa saya } \\
\text { Saya duduk sendiri, sambil melihat-lihat } \\
\text { Melihat dengan asyik } \\
\text { Ke kanan dan ke kiri } \\
\text { Bagaikan tak berhenti, } \\
\text { becak-becak, jalan hati-hati. }\end{array}$} & $\begin{array}{l}\text { Saya mau ikut paman } \\
\text { Berkeliling keliling desa } \\
\text { Hendak melihat perumahanku } \\
\text { Saya cari motornya, } \\
\text { motornya pake helm } \\
\text { Motor-motor saya naik motor }\end{array}$ \\
\hline S2 & & $\begin{array}{l}\text { Saya mau jalan-jalan } \\
\text { Berkeliling Grage Mall } \\
\text { Hendak melihat baju lebaran } \\
\text { Saya manggilan Bunda, Bunda } \\
\text { Ayo kita pergi naik mobil } \\
\text { Aku duduk di depan sambil makan } \\
\text { chiki } \\
\text { Ke kanan dan ke kiri lihat mobilku } \\
\text { jalan } \\
\text { Bagaikan tak berhenti } \\
\text { Bunda, bunda ayo cepat turun }\end{array}$ \\
\hline S3 & & $\begin{array}{l}\text { Saya mau tamasya } \\
\text { Berkeliling keliling komplek } \\
\text { Hendak melihat-lihat orang-orang } \\
\text { yang ada } \\
\text { Saya panggilkan mamah untuk } \\
\text { menjemput saya } \\
\text { Mama...mama ayo jemput saya } \\
\text { Saya duduk di motor sambil } \\
\text { memegang mama } \\
\text { Melihat dengan asyik, ke kanan dan } \\
\text { e kiri dari dan aku } \\
\text { Lihat temanku lari } \\
\text { menyapanya } \\
\text { Teman-teman jangan lari-lari }\end{array}$ \\
\hline S5 & & $\begin{array}{l}\text { Saya mau ke pantai } \\
\text { Berkeliling keliling pantai }\end{array}$ \\
\hline
\end{tabular}




\begin{tabular}{|l|l|}
\hline & $\begin{array}{l}\text { Hendak melihat-lihat pemandang } \\
\text { Saya panggilkan Bunda untuk pergi } \\
\text { melihat pantai } \\
\text { Bunda-bunda ayo pergi }\end{array}$ \\
\hline
\end{tabular}

Berdasarkan data di atas, pada S1 muncul bentuk kreativitas berbahasa siswa, yakni dengan mengubah kata tamasya dengan saya mau ikut paman, kata kota dengan desa, kata naik becak dengan naik motor. Kreativitas berbahasa pada S1 sudah ada yaitu dengan mengubah beberapa kata pada lagu tersebut.

Selanjutnya pada S2 pada lagu "becak", kata tamasya dengan kata jalan-jalan, berkelilingkeliling grage mall, Hendak melihat baju lebaran, Saya manggilan Bunda, Bunda Ayo kita pergi naik mobil, Aku duduk di depan sambil makan chiki, Ke kanan dan ke kiri lihat mobilku jalan, Bagaikan tak berhenti, Bunda, bunda ayo cepat turun. Berdasarkan kutipan tersebut, sudah jelas bahwa S2 megubah liriknya dengan beberapa kosakata baru dan menunjukan adanya kreativitas berbahasa. Berbeda halnya dengan hasil kreativitas pada
S3 yakni Berkeliling keliling komplek, Hendak melihat-lihat orang-orang yang ada, Saya panggilkan mamah untuk menjemput saya, Mama...mama ayo jemput saya, Saya duduk di motor sambil memegang mama, Lihat temanku lari dan aku menyapanya, Teman-teman jangan lari-lari. Sedangkan pada S5 bentuk kreativitasnya berbeda juga yaitu dengan Saya mau ke panta, Berkeliling keliling pantai, Hendak melihat-lihat pemandangan, Saya panggilkan Bunda untuk pergi melihat pantai, Bunda-bunda ayo pergi

Selanjutnya, rekapitulasi kreativitas berbahasa pada siswa di lagu kedua yang berjudul "satu satu aku sayang ibu" adalah sebagai berikut:

Tabel 3

Hasil Kreativitas Berbahasa Siswa Lagu "Satu-satu Aku Sayang Ibu"

\begin{tabular}{|c|l|l|}
\hline Subjek & \multicolumn{1}{|c|}{$\begin{array}{c}\text { Lirik Lagu } \\
\text { "Satu-satu Aku Sayang Ibu" }\end{array}$} & \multicolumn{1}{c|}{ Kreativitas Berbahasa } \\
\hline S7 & $\begin{array}{l}\text { Satu-satu aku sayang Ibu } \\
\text { Dua-dua aku sayang Ayah } \\
\text { Tiga tiga sayang adik kakak }\end{array}$ & $\begin{array}{l}\text { Satu-satu aku sayang nenek } \\
\text { Dua-dua juga sayang kakak } \\
\text { Tiga tiga sayang saudaraku } \\
\text { Satu, Dua, Tiga sayang semuanya }\end{array}$ \\
\hline S9 & Satu dua tiga sayang semuanya & $\begin{array}{l}\text { Satu-satu aku sayang Bunda } \\
\text { Dua-dua juga sayang ayah } \\
\text { Tiga-tiga sayang adik kakak }\end{array}$ \\
\hline
\end{tabular}

Fakultas Keguruan dan Ilmu Pendidikan 


\begin{tabular}{|c|l|l|}
\hline \multirow{2}{*}{$\mathbf{S 1 1}$} & & $\begin{array}{l}\text { Satu dua tiga sayang keluarga } \\
\text { semuanya }\end{array}$ \\
\cline { 3 - 4 } & & $\begin{array}{l}\text { Satu-satu aku naik motor } \\
\text { Dua-dua juga naik mobil } \\
\end{array}$ \\
& $\begin{array}{l}\text { Tiga-tiga naik beca } \\
\text { Satu, dua, tiga naik } \text { kendaraan }\end{array}$ \\
\hline
\end{tabular}

Tabel di atas menunjukkan bahwa ketiga subjek (S7, S9, dan S11) sudah dapat memperlihatkan bentuk kreativitas berbahasanya. Hal ini ditunjukkan dengan mengubah bentuk lirik lagu yang sebenarnya dengan kosakata lain, misalnya Satu-satu aku sayang nenek, Dua-dua juga sayang kakak, Tiga tiga sayang saudaraku. Begitupun ada yang menggantinya dengan Satu-satu aku sayang Bunda Dua-dua juga sayang ayah. Ada satu subjek yang berbeda dengan yang lainnya, yakni dengan kreativitas berbahasanya menjadi Satusatu aku naik motor Dua-dua juga naik mobil, Tiga-tiga naik beca, Satu, dua, tiga naik kendaraan (S11).

Tabel 4

Hasil Kreativitas Berbahasa Siswa Lagu "Balonku"

\begin{tabular}{|c|c|c|}
\hline Subjek & Lirik Lagu "Balonku" & Kreativitas Berbahasa \\
\hline S13 & $\begin{array}{l}\text { Balonku ada lima } \\
\text { Rupa-rupa warnanya } \\
\text { Merah, Kuning Kelabu, Merah muda } \\
\text { dan biru } \\
\text { Meletus balon hijau ...dor } \\
\text { Hatiku sangat kacau } \\
\text { Balonku tinggal empat }\end{array}$ & $\begin{array}{l}\text { Die cast ada lima } \\
\text { Rupa-rupa warnanya } \\
\text { Merah, putih, kelabu, kuning dan } \\
\text { hitam } \\
\text { Rusak die cast putih prak } \\
\text { Hatiku sangat kacau } \\
\text { Die cast ku tinggal empat } \\
\text { Kujaga baik-baik }\end{array}$ \\
\hline S14 & Kupegang erat-erat & $\begin{array}{l}\text { Bukuku ada lima } \\
\text { Rupa-rupa ceritanya } \\
\text { Maling kundang, Keong Mas, } \\
\text { Sangkuriang, Timun Mas } \\
\text { Hilangngnya Buku Keong Mas } \\
\text { Hatiku sangat sedih } \\
\text { Bukuku tinggal empat } \\
\text { Kusimpan dengan aman }\end{array}$ \\
\hline S15 & & $\begin{array}{l}\text { Hewan ada lima } \\
\text { Nama-nama hewannya }\end{array}$ \\
\hline
\end{tabular}




\begin{tabular}{|l|l|l|}
\hline \multirow{5}{*}{$\mathbf{S 1 6}$} & & $\begin{array}{l}\text { Burung, kucing, ayam, bebek dan } \\
\text { angsa } \\
\text { Meletus hewan kucing Dor } \\
\text { Hatiku sangat kacau Hewan tinggal } \\
\text { empat } \\
\text { Kujaga erat erat }\end{array}$ \\
\hline & $\begin{array}{l}\text { Legoku ada lima } \\
\text { Rupa-rupa bentuknya } \\
\text { Persegi, lingkaran, segitiga } \\
\text { Persegipanjang dan kubus } \\
\text { Legoku langsung mental pletuk } \\
\text { Hatiku sangat kaget Legoku tinggal } \\
\text { empat } \\
\text { Kubikin lagi }\end{array}$ \\
\hline
\end{tabular}

Lagu yang ketiga berjudul "Balonku", dalam lagu ini juga kreativitas berbahasa siswa sudah sangat baik, karena memunculkan beberapa kosakata baru dalam lagu tersebut. Seperti terdapat pada data (S13). Pada Subjek 14 mengganti liriknya dengan "bukuku ada lima" Ruparupa ceritanya Maling kundang, Keong Mas, Sangkuriang, Timun Mas Hilangngnya Buku Keong Mas Hatiku sangat sedih Bukuku tinggal empat Kusimpan dengan aman. Kemudian (S15) mengganti liriknya dengan Hewan ada lima Nama-nama hewannya Burung, kucing, ayam, bebek dan angsa
Meletus hewan kucing Dor Hatiku sangat kacau Hewan tinggal empat Kujaga erat erat. Subjek ke 16 menganti liriknya dengan Legoku ada lima Ruparupa bentuknya Persegi, lingkaran, segitiga Persegi panjang dan kubus Legoku langsung mental pletuk Hatiku sangat kaget Legoku tinggal empat Kubikin lagi. Dari keempat subjek tersebut beragam menuliskan bentuk kreativitas berbahasanya, yang dialami oleh siswa sehari-hari pada dunia sekitarnya. Mulai dari mainannya, buku bacaannya, maupun hewan peliharaannya.

Tabel 5

Hasil Kreativitas Berbahasa Siswa Lagu "Naik Kereta Api"

\begin{tabular}{|c|c|c|}
\hline Subjek & Lirik Lagu "Naik Kereta Api" & Kreativitas Berbahasa \\
\hline S19 & $\begin{array}{l}\text { Naik kereta api tut...tut...tut } \\
\text { Siapa hendak turun } \\
\text { Ke Bandung Surabaya }\end{array}$ & $\begin{array}{l}\text { Naik mobil angkot brem, brem, brem } \\
\text { Siapaa hendak ikut } \\
\text { Ke Sumber Harjamukti } \\
\text { Bolehlah naik dengan gratis } \\
\text { Teman-temanku ayo ikut }\end{array}$ \\
\hline
\end{tabular}


BAHTERA INDONESIA:

ISSN 2541-3252

Jurnal Penelitian Pendidikan Bahasa dan Sastra Indonesia

Vol. 4, No. 2, Sep. 2019

\begin{tabular}{|c|c|c|}
\hline & \multirow{3}{*}{$\begin{array}{l}\text { Bolehlah naik dengan percuma } \\
\text { Ayo kawanku lekas naik } \\
\text { Kereta ku tak berhenti lama }\end{array}$} & Angkotnya bentar lagi berangkat. \\
\hline S20 & & $\begin{array}{l}\text { Naik sepeda kring-kring-kring } \\
\text { Siapa tidak ikut keliling kampong } \\
\text { naik sepeda } \\
\text { Bolehlah naik dengan gembira } \\
\text { Ayo kwanku habis naik } \\
\text { Sepedaku ingin dicuci }\end{array}$ \\
\hline S21 & & $\begin{array}{l}\text { Naik bus ber...ber...ber } \\
\text { Siapa hendak ikut } \\
\text { Ke Bandung Yogyakarta } \\
\text { Bolehlah naik dengan percuma } \\
\text { Ayo keluargaku lekas naik } \\
\text { Mobil bis akan segera berangkat }\end{array}$ \\
\hline
\end{tabular}

Berdasarkan hasil temuan dari ketiga siswa (S19, S20, dan S21) didapatkan hasil bentuk kreativitas berbahasanya yaitu dengan mengganti kosakata naik kereta api dengan naik angkot, naik sepeda, dan naik bus. Hal ini tentu saja memberikan gambaran bahwa para siswa tersebut telah mampu mengembangkan daya kreativitas berbahasanya dengan mencoba memberikan istilah atau kosakata lain selain dari kosakata asal yang ada pada lirik lagu tersebut.

Tabel 6

Hasil Kreativitas Berbahasa Siswa Lagu "Bangun Tidur"

\begin{tabular}{|c|c|c|}
\hline Subjek & Lirik Lagu "Bangun Tidur" & Kreativitas Berbahasa \\
\hline S24 & $\begin{array}{l}\text { Bangun tidur } k \text { uterus mandi } \\
\text { Tidak lupa menggosok gigi } \\
\text { Habis mandi ku tolong ibu } \\
\text { Membereskan tempat tidurku }\end{array}$ & $\begin{array}{l}\text { Bangun tidur kuterus sahur } \\
\text { Tidak lupa shalat di masjid } \\
\text { Sholat kuterus ngajiSupaya hafal al } \\
\text { Quran } \\
\text { S25 Bangun Tidur } \\
\text { Bangun tidur kuterus makan } \\
\text { Tidak lupa puasa penuh } \\
\text { Habis sahur menunggu imsak }\end{array}$ \\
\hline $\mathrm{S} 25$ & & $\begin{array}{l}\text { Bangun tidur kuterus makan } \\
\text { Tidak lupa puasa penuh } \\
\text { Habis sahur menunggu imsak }\end{array}$ \\
\hline S26 & & $\begin{array}{l}\text { Bangun tidur kuterus sholat } \\
\text { Tidak lupa wudhu dulu }\end{array}$ \\
\hline
\end{tabular}




\begin{tabular}{|c|c|}
\hline & $\begin{array}{l}\text { Habis sholat kuterus mandi } \\
\text { Tidak lupa menggosok gigi }\end{array}$ \\
\hline S27 & $\begin{array}{l}\text { Habis tidur kuterus sahur } \\
\text { Tidak lupa kuliah shubuh } \\
\text { Habis buka kuterus sholat } \\
\text { Shalat taraweh bersama teman }\end{array}$ \\
\hline S28 & $\begin{array}{l}\text { Bangun tidur kuterus wudhu } \\
\text { Tidak lupa sholat di masjid } \\
\text { Habis sholat kuterus mandi } \\
\text { Biar badanku tidak bau }\end{array}$ \\
\hline S29 & $\begin{array}{l}\text { Bangun tidur kuterus sholat } \\
\text { Tidak lupa wudhu duluan } \\
\text { Habis mandi ku berangkat sekolah } \\
\text { Tidak lupa salim ke orang tua }\end{array}$ \\
\hline
\end{tabular}

Tabel di atas menunjukan bentuk kreativitas berbahasa pada siswa ( S24, S25, S26, S27, S28, dan S29) dalam lagu “Bangun Tidur”. Di sana ada beberapa subjek yang menuliskan setelah bangun tidur terus salat, yang diawali dengan berwudu, tetapi ada juga yang kreativitas berbahasa para siswa. menuliskannya dengan bangun tidur kuterus makan. Hal tersebut berbeda-beda sesuai dengan ide yang terdapat pada benak siswa. Dengan demikian, ide-ide yang muncul tersebut memberikan warna lain dalam Tabel 7

Hasil Kreativitas Berbahasa Siswa Lagu "Anak Gembala"

\begin{tabular}{|l|l|l|}
\hline Subjek & \multicolumn{1}{|c|}{ Lirik Lagu "Anak Gembala" } & \multicolumn{1}{|c|}{ Kreativitas Berbahasa } \\
\hline S30 & Aku adalah anak gembala & Aku adalah anak yang pintar \\
& Selalu riang serta gembira & Selalu belajar setiap hari \\
& Karena aku \\
& Karena aku pengembala & Ayolah belajar, belajar \\
& Tak pernah lelah ataupun sendiri & Akulah anak yang pintar \\
& Tralalala ...lalala..lalalala belajar setiap waktu \\
& & Karena aku senang belajar \\
& & Tak pernah malas ataupun lelah \\
& & Lala...la...la...la...la \\
& & Setiap hari selalu belajar \\
& Dipadang rumput bersama teman- \\
& & teman \\
& & La...lalalalalalala \\
& &
\end{tabular}




\begin{tabular}{|c|c|}
\hline S32 & $\begin{array}{l}\text { Aku adalah anak yang rajin } \\
\text { Selalu belajar tak lupa sholat } \\
\text { Karena aku rajin belajar tak pernah } \\
\text { balas dan juga malas } \\
\text { Syalalalalalalala... } \\
\text { Setiap hari aku sekolah } \\
\text { Selalu riang serta gembira } \\
\text { Syalalalala.... }\end{array}$ \\
\hline S33 & $\begin{array}{l}\text { Aku adalah anak yang pintar } \\
\text { Selalu dapat rangking di kelas } \\
\text { Larena aku senang belajar } \\
\text { Tak pernah malas ataupun lelah } \\
\text { Talalallalalal } \\
\text { Setiap hari kubawa buku kemana } \\
\text { saja } \\
\text { Aku mau pergi akhirnya aku jadi } \\
\text { professor } \\
\text { Yang selalu dikenang semua orang } \\
\text { Tralalallalalala }\end{array}$ \\
\hline S34 & $\begin{array}{l}\text { Aku adalah anak yang rajin } \\
\text { Ngerjain tugas setiap hari } \\
\text { Karena aku senang belajar } \\
\text { Tak pernah malas ataupun bolos } \\
\text { Belajar ayo belajar ayo terus belajar } \\
\text { Setiap hari ku baca buku } \\
\text { Supaya dapat nilai seratus } \\
\text { Guruku hebat mengajar saya } \\
\text { Supaya cerdas dan juga pintar } \\
\text { Belajar ayo belajar ayo terus belajar }\end{array}$ \\
\hline
\end{tabular}

Berdasarkan tabel 7 mengenai bentuk kreativitas berbahasa pada anak yang terdapat dalam lagu "Anak Gembala" menunjukan bentuk kreativitas bahasa yang beragam. Beberapa subjek menggantinya dengan kosakata "aku adalah anak yang rajin" ataupun "aku adalah anak yang pintar". Terlihat dari beberapa temuan di atas, bahwa subjek sudah mampu mengembangkan kreativitas berbahasanya. Diawali dengan hal-hal sederhana yang sering dialami dalam kehidupan sehari-harinya. Dengan demikian, penggunaan media lagu anak sangatlah efektif untuk menambah perbendaharaan bahasa anak dan mengembangkan bentuk kreativitas berbahasanya. Lagu anak dianggap paling mudah dan sederhana karena sejak usia balita mereka sudah mulai diperkenalkan 
dengan lagu anak-anak. Sehingga, saat anak berusia 9 hingga 10 tahun begitu pesat perbendaharaan kosakatanya. Hal ini dibuktikan dengan kemampuan siswa mengubah beberapa lirik kosakata dari lagu anak tersebut, yang menunjukan kreativitas berbahasa anak. Wujud kreativitas berbahasa ini tentu saja harus terus dikembangkan agar ragam kosakata yang ada dalam diri anak semakin banyak. Selain itu, kreativitas berbahasa ini juga berimplikasi positif terhadap peningkatan daya nalar dan berpikir kritis anak.

\section{SIMPULAN}

Dari beberapa temuan di atas dapat disimpulkan hal-hal sebagai berikut.

1. Subjek sudah mampu mengembangkan kreativitas berbahasanya. Diawali dengan hal-hal sederhana yang sering dialami dalam kehidupan sehari-harinya. Dengan demikian, penggunaan media lagu anak sangatlah efektif untuk menambah perbendaharaan bahasa anak dan mengembangkan bentuk kreativitas berbahasanya. Selain itu, keterampilan mendengarkan, menyimak, membaca, dan menulis saling memiliki keterkaitan dalam penggunaan media lagu anak ini untuk meningkatkan kreativitas berbahasa.

2. Dari beberapa lagu yang dipilih, yaitu Becak, Satu-satu aku sayang Ibu, Balonku, Naik kereta api, Bangun tidur, dan Aku anak Gembala anak-anak sudah mampu mengubah beberapa lirik lagunya. Lagu anak dianggap paling mudah dan sederhana karena sejak usia balita mereka sudah mulai diperkenalkan dengan lagu anak-anak. Sehingga, saat anak berusia 9 hingga 10 tahun (kelas 4 SD) begitu pesat perbendaharaan kosakaanya. Hal ini dibuktikan dengan kemampuan siswa mengubah beberapa lirik kosakata dari lagu anak tersebut, yang menunjukan kreativitas berbahasa anak.

\section{DAFTAR PUSTAKA}

Asrori, Muhamad. 2010. Psikologi Pembelajaran. Bandung: CV Wahana Prima.

Douglas, Brown. 2008. Prinsip Pembelajaran dan Pengajaran Bahasa. Jakarta: Pearson Education.

Mahsun. 2014. Teks dalam Pembelajaran Bahasa Indonesia Kurikulum 2013. Jakarta: Grafindo Persada.

Mussen, Paul Henry, dkk. 2010. Perkembangan dan Kepribadian Anak. Jakarta: Erlangga.

Susilan, Rudi dan Cepi Riyana. 2009. Media Pembelajaran: Hakikat, 
BAHTERA INDONESIA:

ISSN 2541-3252

Jurnal Penelitian Pendidikan Bahasa dan Sastra Indonesia

Vol. 4, No. 2, Sep. 2019

Pengembangan, Pemanfaatan, dan Yunus, Abidin. 2012. Pembelajaran Bahasa Penilaian. Bandung: CV Wacana Berbasis Pendidikan Karakter. Prima. Bandung: Refika Aditama. 